\title{
Establishing a web-based measurement of aggression (WTCRTT): Examining the validity of a modified Taylor's competitive reaction time test
}

\author{
Joon-Ho Kang, Choong Hoon Lim¹, Young Ik Suh², Alex C. Gang ${ }^{3 *}$ \& Paul M. Pedersen ${ }^{4}$ \\ ${ }^{1}$ Professor, Seoul National University, Seoul, Republic of Korea \\ ${ }^{2}$ Assistant Professor, University of West Georgia, Georgia, United States \\ ${ }^{3}$ Associate Instructor, Indiana University-Bloomington, Indiana, United States \\ ${ }^{4}$ Professor, Indiana University-Bloomington, Indiana, United States
}

\begin{abstract}
The current study attempted to develop a web-based state aggression measurement program (WTCRTT) and examine its applicability in terms of validity and reliability by conducting laboratory experiments. A repeated experimental design was employed, where subjects were exposed to both violent and non-violent media content. A physiological measure was also included to test the internal validity of media stimulation. The results showed the WTCRTT is a valid measure of behavioral aggression as the hypotheses on construct validity and internal validity were supported. For instance, the WTRCTT after exposure to violent media was positively correlated to anger, physical aggression, and total trait aggression scores. The WCRTT that was developed and tested in this study can be used not only by the scholars interested in aggression research with no cost and but also by the parents who want to monitor their children's state (i.e., behavioral) aggression.
\end{abstract}

Key words: aggression, media violence, Web-based TCRTT, internal validity, gender differences

\section{Introduction}

Aggression is a research topic that is often studied in social science (e.g., Anderson \& Dill, 2000; Beal, Weiss, Barros, \& MacDermid, 2005; Konijin, Bijvank, \& Bushman, 2007; Tremblay, Vitaro, \& Côté, 2018). For instance, numerous scholars such as Bernat,

Submitted : 14 January 2020

Revised : 11 February 2020

Accepted : 27 February 2020

Correspondence : cgang@iu.edu
Calhoun, Adams, and Zeichner (2001), Bond and Lader (1986), Bushman (1995), and Coyne et al., (2018) have examined the link between exposure to violent media and aggressive behaviors. Furthermore, given the concerns surrounding youth violence around the world, over the past dozen years or so there has been increased interest in pinpointing the causal relations of youth aggression (e.g., Anderson \& Murphy, 2003; Doob \& Sprott, 1998; Stadler, Rohrmann, Steuber, \& Roustka, 2006).

Aggression research can be categorized into two 
unique approaches: applied field research and laboratory experimental research. There has been an ongoing controversy regarding the strengths and weaknesses of each type in terms of internal and external validity (Anderson, Lindsay, \& Bushman, 1999). While some have argued that experimental studies have lower external validity (i.e., generalizability) than do field studies, Anderson and Bushman (1997), using the meta-analysis method, supported the external validity of laboratory research by finding correspondence in key variables between laboratory research and field research. The external validity of laboratory aggression research is further confirmed by Anderson, Lindsay, and Bushman (1999), who found significant consistency between field research and laboratory experiment.

While laboratory experiment is as externally valid as field study, defenders of laboratory research acknowledge the importance of the interplay between field research and research using laboratory experiment, as the real world is the best place to examine and apply new phenomenon (Anderson \& Bushman, 1997). On the other hand, laboratory aggression research is known to be a useful method because of effective control for external variables, while aggressive behaviors tend to be more intensified in the laboratory setting (Anderson \& Bushman). As a consequence, there is a need for a quasi-experimental design (i.e., experimental study in real setting) which can broaden our understanding on aggression by bridging the gap between field study investigations and laboratory experimental research. However, the existing lab-based aggression measurement endeavors are designed for single-laboratory experiments and, thus, cannot be applied to field-experimental studies in real settings as the equipment is often cost prohibitive (Farrar \& Krcmar, 2006). In addition, it has been argued that these measures are very time-consuming to administer (Farrar \& Krcmar) and may draw uncomfortable attention to the participants in terms of using electronic shocks (Ferguson \& Rueda, 2009).

With the advances in wireless and Internet technology, the current study attempts to develop a user-friendly web-based aggression measurement program, which can be utilized for field-experimental aggression study. Participants have a chance to punish an imaginary opponent by administering noise blasts (i.e., clicking mouse button), similar to the traditional aggression measurement methods. The aggression measurement program developed in the current study differs from the traditional method in that noise blasts were applied here instead of electronic shocks. Noxious stimuli such as noise blasts have been already employed in the previous studies (e.g., Achterberg, van Duijvenvoorde, Bakermans-Kranenburg, \& Crone, 2016; Anderson \& Murphy, 2003; Bushman, 1995; Konijin et al., 2007), while the validity of noise-blasts has not been fully examined to date. It was suggested using noise blasts is beneficial as it leads to fewer ethical concerns and it is practical as it enables researchers to conduct their investigations with personal computers (Ferguson \& Rueda, 2009).

In addition, the aggression measurement program developed in the present study should be beneficial, as there has been a need for a standardized measurement tool. It has been argued that one of the critical methodological problems in experimental aggression research is that there is no standardized measurement format such as different apparatuses (Ferguson \& Rueda, 2009). Thus, the program developed in the study may be a useful tool for future aggression studies as the program is available for any scholars interested in experimental aggression research, creating consistency in research findings between studies. In particular, the measurement can be an efficient tool for cross-cultural aggression studies in that identical measurement programs can be applied in two different laboratory settings. This is important because there have been calls for cross-cultural aggression research and it is assumed that cultural differences and perceptions of violence would influence the study results (Ferguson \& Rueda). 
Direct Physical Aggression as a Measure of Aggression

Although there are some limitations of behavioral measurement of aggression such as cost and time, various types of physical aggression have been applied to test the short-term aggression in experimental studies. Among these applications, three particular approaches - Machine Paradigm (Buss, 1961), Berkowitz (1962), and Competitive Reaction Paradigm (1967) - are known as the most popular measures of aggression. The first two approaches are similar in that subjects play roles as aggressors, while confederates are those individuals who receive different types of punishment (e.g., electric shocks) in non-competitive situations. For example, in the Machine Paradigm, the participant played the role of the teacher, while the confederate played the role of the learner, thus creating a non-competitive situation. During the experiment, the participant was notified that s/he would have a chance to penalize the confederate with noxious stimuli whenever the confederate answered a question incorrectly. Similarly, in the study by Berkowitz, a participant, or "observer," was informed that s/he would be allowed to evaluate another individual's performance ("performer") during certain tasks using electric shocks based on the observer's view of the performer's performance. In this paradigm, the number of electric shocks was considered the measure of the observers' aggression.

Taylor's Competitive Reaction Test (TCRTT; Taylor, 1967) is similar to the above two approaches (Berkowitz, 1962; Buss, 1961) in terms of the intensity/duration of shocks as an indication of aggression. However, the TCRTT is a unique paradigm as participants play the reaction time game in a competitive situation, where subjects also receive punishment (e.g., listening to noise blasts). At the beginning of each trial, each participant selects the shock level to be received by the slower responding person, so the subject receives a certain level of punishment chosen by his/her opponent. This competitive reaction time paradigm has been employed and adapted in several studies related the media violence (Anderson \& Dill, 2000; Anderson \& Murphy, 2003; Beal et al., 2005; Bernat et al., 2001; Bond \& Lader, 1986; Bushman, 1995; Giancola \& Zeichner, 1995; Gustafson, 1991; Zeichner \& Phil, 1979).

Based on the merits described above, the program developed in this study (called the "Web-based TCRTT" [WTCRTT]) is based on Taylor's Competitive Reaction Time Test (TCRTT, 1967). With the TCRTT, the participant competes against a fictitious opponent in a reaction-time task. The person who responds slower is punished with an electric shock or noise blasts in which the levels of punishment (e.g., intensity, duration) are operationalized as the aggression level (e.g., Anderson, 1995; Ferguson, Smith, Miller-Stratton, Fritz, \& Heinrich, 2008; Konijin et al., 2007). Furthermore, the utilization of noise blast as the punishment mechanism enables attaining both practicality and ethicality in the research process (Ferguson \& Rueda, 2009). Despite its popularity as an assessment tool, only a few studies have examined its validity to date (Giancola, \& Zeichner, 1995; Ferguson, Smith, Miller-Stratton, \& Heinrich, 2008). Furthermore, those studies reported contradictory results regarding the validity of the TCRTT. For example, Giancola and Zeichner (1995) found significant correlations between shock intensity and trait aggression. Conversely, Ferguson et al., (2008) did not find significant correlations between trait measures and the TCRTT and called for research on validity of the program itself.

It should be noted, however, that that the failure to find the linkage could be in part due to methodological problems such as a failure to separate sub factors of the trait measures of aggression in the data analysis. The studies on validity of the TCRTT (e.g., Ferguson \& Rueda; 2009; Ferguson et al., 2008; Giancola \& Zeichner, 1995) utilized the Buss-Durkee Hostility Inventory (BDHI, 1967) or its shorter version. The BDHI has four sub factors, including Physical Aggression (PA), Hostility (H), Verbal Aggression 
(VA), and Anger (A). Although "behavior" and "intention to harm" are two important elements in the definition of aggression (Baron \& Richardson, 1994), the TCRTT should be more closely related to the PA sub factor in the BDHI than to the other factors (Taylor, 1967). Furthermore, non-significant relations of the TCRTT with other sub factors should not curtail the value of the measurement.

Additionally, the previous studies noted above did not consider the influence of gender on the TCRTT. There is an abundance of evidence that supports the postulation that males are more violent than females and thus it is reasonable to assume that male subjects will show higher levels of aggression in both conditions (i.e., violent \& non-violent conditions) (e.g., Clemente, Espinosa, \& Vidal, 2008; Reidy, Dimmick, MacDonald, \& Zeichner, 2009). Based on the findings of previous research, the following two hypotheses were postulated and tested:

Hypothesis 1: There is a positive correlation between Web-based TCRTT (WTCRTT) and Physical Aggression (PA) of BDHI.

Hypothesis 2: Males showed higher levels of both violent media content (VWTCRTT) and non-violent media content (NVWTCRTT) than females.

In addition, the current study adds to the body of literature in aggression research as it is one of the first known attempts to examine the internal validity of the TCRTT. Previous studies employed the correlational method (i.e., examine the correlations between trait aggression and the TCRTT) and, therefore, their focus has been on the construct validity of the program (e.g., Ferguson \& Rueda, 2009; Ferguson et al., 2008; Giancola \& Zeichner, 1995). As explained by Gay (1987), construct validity refers to the "degree to which a test measures an intended hypothetical construct" (p. 131). While the studies noted above did broaden our understanding of the TCRTT, little is still known about the internal validity of the TCRTT, which is also an important aspect in validity issues. Internal validity is especially important in experimental study as defenders of experimental aggression research often consider the internal validity as the most important strength of experimental aggression research because of smaller alternative explanations of causal relations (e.g., Anderson \& Bushman, 1997; Anderson et al., 1999).

Internal validity is defined as the "condition that observed differences on the dependent variable are a direct result of manipulation of the independent variable” (Gay, 1987, p. 265). In order to examine the internal validity of the TCRTT, this study employed a repeated experimental design where each subject was exposed to both violent and non-violent media and his/her responses to each manipulation were compared. As mentioned earlier, the influence of media violence on aggression has been well documented (Anderson, Berkowitz, Donnerstein, Huesmann, Johnson, Linz, Malamuth, \& Wartella, 2003; Bushman, 1995; Funk, Baldacci, Pasold, \& Baumgardner, 2004; Slater, Henry, Swaim, \& Anderson, 2003). Thus, while the studies noted above examined the influence of media violence on aggression prospectively, the present study retrospectively examined the internal validity of measures by testing individual responses to violent and non-violent media stimuli. Therefore, a third hypothesis was created and tested in this study:

Hypothesis 3: Subjects showed higher level of WTCRTT with the exposure to violent media content (VWTCRTT) than with WTCRTT with the exposure to nonviolent media content (NVWTCRTT).

\section{Method}

The sample for this study included 97 participants who were children between the ages of 10 and 16. All subjects were recruited by advertisements which were placed in a local newspaper over a four-week period in a Midwestern city. After becoming aware of the 
advertisement, parents/guardians interested in having their child participate contacted the researchers either by phone or e-mail. Females comprise 41.2 percent (n $=40$ ) of the sample, while mean age was 12.74 (range $=10-16, S D=1.90$ )

\section{Measures}

The Web-based Competitive Reaction Time Test (WCRTT) is a Flash-based program (hereafter referred to as "game") that can be loaded on a PC or Macintosh. At the beginning of the game, the subject selects the level of noise which is placed on the right side of the screen. The subject is informed that $\mathrm{s} / \mathrm{he}$ will play against an opponent but, in fact, s/he is playing against the computer program/game, where the number of wins and losses is predetermined. This number is predetermined as the noise blasts the subject receives can serve as a form of provocation. The WCRTT is programmed for subjects to win five times out of 12 $\mathrm{RT}$ and the winning trial is randomized to minimize the ordering effects. The noise level set by each subject is operationalized as the level of aggression, ranging from 10 (e.g., $105 \mathrm{~dB}$ ) to 0 (e.g., $60 \mathrm{~dB}$ ). After selecting the intensity of the noise level, the subject clicks the start button in the middle of the screen. Then the subject clicks the square button as fast as possible when the color of square button turns red. In order to reduce the potential audio distractions from the experimental administrator and other study participants, each subject wears headphones. Furthermore, in order to create a more competitive situation, the subject sees a text message informing him/her that his/her reaction time is slower than the person against whom s/he has been playing, all the while hearing a very noisy sound after every losing trial. On completion of the 12 RTs, the results of each trial are shown on the screen (i.e., wins/losses with intensity levels) and those scores were saved on a hard drive for retrieval for data analysis.

In addition to the data secured from subjects' participation in the WCRTT, this study collected data through the use of the Aggression Questionnaire (developed by Buss \& Perry, 1992) in order to measure trait aggression. The Aggression Questionnaire (AQ) is a revised version of the Buss-Durkee Hostility Inventory (Buss \& Durkee, 1957). The AQ has a total of 29 questions using a 5-point Likert-type scale ranging from 1 (extremely uncharacteristic of me) to 5 (extremely characteristic of me). The AQ includes four subscales: Physical Aggression (PA), Verbal Aggression (VA), Anger (A), and Hostility (H). Buss and Perry (1992) reported that the coefficient alpha for the AQ is .89, and the test-retest correlation is .80 .

Lastly, the heart rate of the subjects was measured to test the internal validity of the media stimulation. Heart rate was tested by placing a Polar WearLink ${ }^{\circledR}+$ 31 coded transmitter belt on the subject's chest after cleaning the contact surface of transmitter belt to control the dehydration of skin. Signals from the belt were transmitted and automatically recorded to a Polar Eletro RS400 heart rate monitor, and then the heart rate data were transferred and stored on a computer. Poels and Dewitte (2006) pointed out several advantages of autonomic measures such as heart rate including measurement in real time without any cognitive biases and measurement of low order emotions.

\section{Procedure}

This investigation first involved a pilot study, followed by the main study. The primary purpose of the pilot study was to examine the reliability and validity of the scaled measures and media stimuli. The subjects in the pilot study were excluded from the main study. Subjects filled out the self-administered survey; they were exposed to both violent and non-violent media stimuli; they played the WCRTT after each media exposure; and they were asked a series of questions as a form of an exit interview. There were five pilot sessions where all elements of the study, including the survey and media stimuli, were revised based on the subjects' feedback. For instance, it was found that 
including both noise intensity and duration made the task a little too difficult for some subjects, especially the younger ones. Furthermore, it has been suggested that there is a need for a standardized measurement, while noise intensity might be the best indicator (Ferguson et al., 2008). Thus, the current study utilized only the noise intensity. Likewise, some questions in the scaled measure were hard for some younger subjects to understand and thus, those items were revised.

The main study involved similar steps and procedures. When subjects arrived at the computer lab with their parents/guardians, informed consent and assent were obtained by both the subjects and their parents/guardians. They also provided their demographic information. The main experiment in this study utilized a randomized repeated experimental design, where study subjects were randomly assigned to one of four media content conditions (i.e., violence/violence, non-violence/ violence, violence/non-violence, and non-violence/nonviolence). The main experiment was conducted in a lab setting in groups of five or less. Subjects were instructed to sit at computer monitor to read instructions related to the experimental protocols. The experiment administrators answered participants' questions regarding the study and confirmed their grasp of the instructions prior to the commencement of the baseline tasks. Subjects then completed a series of baseline tasks, such as listening to meditation music. The purpose of the baseline tasks was to control baseline emotion and arousal. This phase took approximately three minutes to complete. Following the baseline tasks, subjects were exposed to media content through an LCD monitor in the lab. Their levels of state aggression were measured during/after each media stimuli. Video clips from a mixed martial arts (MMA) competitive match and an aggressive cartoon movie were used as violent media stimuli while a figure skating championship and a non-violent cartoon movie were used as non-violent media content. Each clip was edited to last for about 10 minutes.

During and after the exposure to each stimulus material, participants' aggression levels were tested with the WCRTT in order to investigate the internal validity of the program. In addition, subjects' heart rates were measured during the total experiment session in order to assess the internal validity of the stimulus materials, similar to methods used by Lang (1990). Furthermore, some variables, including consumption of caffeinated drinks, involvement in exercise, and television viewing on the day of the experiment were controlled. Previous studies have suggested that those factors directly and indirectly influence subjects' levels of arousal (Labrie et al., 2003). As explained below, the average scores of the WCRTT were used as indices for internal validity of the stimulus materials.

\section{Results}

\section{Reliability}

The overall Web-based Competitive Reaction Time Test (WCRTT) and two subscales of WCRTT showed satisfactory levels consistent with previous studies (Bushman, 1995; Buss and Perry, 1992; Giancola \& Zeichner, 1995), while two other subscales reached acceptable reliability levels. Specifically, the subscales of Physical Aggression (PA) and Anger (A) reached alpha levels of .84 and .76 respectively, while the subscales of Hostility $(\mathrm{H})$ and Verbal Aggression (VA) reached alpha levels of .73 and .62 respectively. The WCRTT also showed high levels of internal consistency as the WCRTT after the exposure to violent media (VWCRTT) reached an alpha level of .94, while the WCRTT after the exposure to the non-violent media (NVWCRTT) reached an alpha level of .95.

\section{Internal Validity of Media Stimulation}

A Repeated Measures Design (RMD) was utilized, given that the same dependent variables were measured after each media stimulation (i.e., violent and non-violent video clips). The mean heart rate was used as a measure of arousal levels. It has been argued in previous research that media violence increases the 
arousal levels (Bushman, 1995). Several advantages of the repeated design were reported, including reducing unsystematic variability and providing greater power (Scariano \& Davenport, 1987). In the present study, Mauchly's test could not estimate levels of significance in terms of the variance in the differences between treatment conditions, because the current research had only two repeated measures, and thus the degrees of freedom were corrected by the Greenhouse-Geisser estimates of sphericity $\left(\varepsilon^{2}=1\right)$. In line with expectations, subjects showed significantly higher arousal levels after the exposure to the violent media stimulations $(M=89.78, s d=1.29)$ than after the exposure to the non-violent media stimulations $(M=$ 87.55, $s d=1.18)(F=40.88, d f=1, p<.05)$.

\section{Validity of WTCRTT}

The data support construct validity of the WCRTT as the VWCRTT is positively correlated with AQA ( $r$ $=.22, p<.05)$, AQPH $(r=.22, p<.05)$, and total AQ $(r=.20, p<.05)$. However, as illustrated in Table 1 , it was not significantly correlated with $\mathrm{AQH}$ and AQVA. On the other hand, as shown in Table 2, NVWCRTT was not significantly correlated with any subscales of trait aggressiveness (See table 2). This finding is consistent with expectations.

Table 1. Zero-order Correlations between WWCRTT, AQA, $A Q P A, A Q H, A Q V A$, and AQTOTAL

\begin{tabular}{lcccccc}
\hline \hline & VWCRTT & AQA & AQPA & AQH & AQVA & AQTOTAL \\
\hline VWCRTT & 1 & $.23^{*}$ & $.23^{*}$ & $.07^{*}$ & $.07^{*}$ & $.22^{*}$ \\
AQA & & 1 & $.61^{*}$ & $.52^{*}$ & $.54^{*}$ & $.88^{*}$ \\
AQPA & & & 1 & $.30^{*}$ & $.27^{*}$ & $.81^{*}$ \\
AQH & & & 1 & $.35^{*}$ & $.69^{*}$ \\
AQVA & & & 1 & $.62^{*}$ \\
AQTOTAL & & & & & 1 \\
\hline \hline$N=91$ & & & & \\
$*$ * 05 & \\
Note: VWCRTT = Violence Web based Competitive Reaction Time \\
Test; AQA = Aggression Questionnaire-Anger; AQPA = Aggression \\
Questionnaire-Physical Aggression; AQH = Aggression Questionnaire- \\
Hostility; AQVA=Aggression Questionnaire-Verbal Aggression; AQTOTAL \\
$=$ Aggression Questionnaire Total Score
\end{tabular}

Table 2. Zero-order Correlations between NWWCRTT, AQA, $A Q P A, A Q H, A Q V A$, and AQTOTAL

\begin{tabular}{lcccccc}
\hline \hline & NVWCRTT & AQA & AQPA & AQH & AQVA & AQTOTAL \\
\hline NVWCRTT & 1 & $.07^{*}$ & $.10^{*}$ & $.06^{*}$ & $.08^{*}$ & $.10^{*}$ \\
AQA & & 1 & $.61^{*}$ & $.52^{*}$ & $.54^{*}$ & $.88^{*}$ \\
AQPA & & & 1 & $.30^{*}$ & $.27^{*}$ & $.81^{*}$ \\
AQH & & & & 1 & $.35^{*}$ & $.69^{*}$ \\
AQVA & & & & & 1 & $.62^{*}$ \\
AQTOTAL & & & & & & 1 \\
\hline N $=91$ & & & & & & \\
$*<.05$ & & & & & &
\end{tabular}

Note: NVWCRTT $=$ Non-Violence Web based Competitive Reaction Time Test; $\mathrm{AQA}=$ Aggression Questionnaire-Anger; $\mathrm{AQPA}=$ Aggression Questionnaire-Physical Aggression; AQH = Aggression QuestionnaireHostility; AQVA= Aggression Questionnaire-Verbal Aggression; AQTOTAL

= Aggression Questionnaire Total Score

Furthermore, the repeated measures design was employed to examine if there is a significant difference between VWCRTT and NVWCRTT, based on the previous findings that exposure to the media violence increases the level of aggression. Although the present study did not find a significant main effect, mean data suggest subjects showed higher levels with the VWCRTT $(M=65.65, s d=29.13)$ than with the NVWCRTT $(M=$ 62.13, $s d=27.43$ ). Additionally, there was a significant mean difference on both the VWCRTT and the NVWCRTT between males and females, which is consistent with findings from scholars such as Clemente, Espinosa, and Vidal (2008), Marsee, Weems, and Taylor (2008), and Reidy, Dimmick, MacDonald, and Zeichner (2009). For instance, male subjects $(M=74.02, s d=30.01)$ showed higher levels of VWCRTT than their female counterparts $(M=53.75 . \quad s d=23.29) \quad(t=3.57, \quad d f=95, \quad p<.05)$. Likewise, the males $(M=69.88, s d=26.71)$ showed higher levels of NVWCRTT than the female subjects ( $M$ $=51.1, s d=24.57)(t=3.52, d f=95, p<.05)$.

Table 3. WTCRTT Scores and Gender

\begin{tabular}{lccc}
\hline \hline & Male & Female & $t$ value \\
\hline VTWCRTT & $74.02(3.01)$ & $53.75(23.29)$ & $3.57^{*}$ \\
NVWCRTT & $69.88(26.71)$ & $51.1(24.57)$ & $3.52^{*}$ \\
\hline$*<.05$ & & &
\end{tabular}

Note: VWCRTT $=$ Violence Web based Competitive Reaction Time Test; NWCRTT=Non-Violence Web based Competitive Reaction Time Test 


\section{Discussion}

While Taylor's Competitive Reaction Time Test (TCRTT) is one of the most popular measures of aggression in media research, there have been calls for re-examining its validity and reliability as only handful of studies have examined its applicability, while even those studies reported contradictory results (Ferguson et al., 2008; Giancola \& Zeichner, 1995). On the other hand, scholars (Tedeschi \& Quigley, 1996) have pointed out some limitations such as cost and administration issues related to the TCRTT. In response to the various issues noted above, the current study developed the Web-based TCRTT (WTCRTT) - which is an integration of a web-based program and the TCRTTbased aggression measurement - and examined its applicability in terms of reliability and validity.

Overall, all three hypotheses were supported. For instance, we found significant correlation between WTCRTT and scaled measures of aggression (H1). Further, it was found that there was a gender difference (H2), while subjects WTCRTT score was significant higher with the exposure to violent media contents (H3). The first hypothesis (H1) examined the relationship between trait aggressiveness and the WTCRTT. Interestingly, the WTCRTT after the exposure to violent media (VWTCRTT) had a significant correlation with BDHI, while the WTCRTT after the exposure to non-violent media (NVWTCRTT) did not have positive relationships with all BDHI subscales. It should be pointed out that provocation plays an important role in experimental aggression studies as it will trigger the aggressive behaviors to occur (Giancola \& Zeichner, 1995). In other words, no significant difference is expected in violent behaviors between high aggressive subjects and low aggressive subjects when there is no provocation (i.e., condition with non-violent media). Thus, it is reasonable to assume that the inconsistent findings from previous studies may be due in part to the failure to manipulate the provocation conditions. The present study is one of the first known attempt to measure aggression where subjects are exposed to both provoked (i.e., violent media) and non-provoked (i.e., non-violent media) conditions with a repeated measure design.

In particular, although a significant relationship between the VWTCRTT and the Physical Aggression (PA) subscale was expected (as illustrated in the second hypothesis [H2]), the analysis revealed that the VWTCRTT is significantly related with total BDHI and the Anger (A) subscale as well. Furthermore, as expected, there was no significant correlation of the VWTCRTT with the subscales Verbal Aggression (VA) and Hostility (H). Such a finding supports some previous research (e.g., Ferguson et al., 2008; Giancola \& Zeichner, 1995) on the traditional TCRTT that not all trait aggressiveness is correlated to the behavioral measures of aggression. This finding also provides face validity as the TCRTT paradigm focuses on situations (i.e., is situation based), whereas trait measures focuses on the individual differences.

With regard to the gender difference in terms of levels of the WTCRTT, males showed higher scores in both the VWTCRTT and the NVWTCRTT scores than did their female counterparts (H3), which also showed the validity of WTCRTT. As noted in the paragraphs above, previous studies have documented gender differences in aggression (e.g., Clemente et al., 2008; Marsee et al., 2008; Reidy et al., 2009). A variety of individual and environmental influences of aggression have been documented, including personality (Bushman, 1995; Gunter, 1994; Krcmar \& Greene, 1999), parental influences (Nathanson, 1999), and social class (Frost \& Stauffer, 1987). Among those factors, the current study utilized gender as one of the most apparent influences of aggression with plenty of evidence from previous studies (Burton, Henninger, Hafetz, \& Cofer, 2009; Haridakis, 2006; Marsee et al., 2008; Ostrov, Gentile, \& Crick, 2006; Reidy et al., 2009). Thus, the consistency between the previous studies and the current study confirms the WTCRTT as a valid measure of aggression. The current study 
utilized violent/nonviolent media as main manipulation as there is a plenty of evidence that violent media contents lead to aggressive behaviors (Anderson, Berkowitz, Donnerstein, Huesmann, Johnson, Linz, Malamuch, \& Wartella, 2003; Christensen \& Wood, 2007; Sherry, 2001). However, it would be fruitful, if future studies use different treatments such as interpersonal provocation or frustration paradigm.

Consistent with expectations, the results also revealed the subjects' VWTCRTT score was higher than their NVWTCRTT score, although the difference was not significant. One explanation for not finding a significant difference here is the subjects' intentions to be consistent between two conditions. The experimental condition employed in the present study was carefully designed to minimize the 'carry-over' effects by having a baseline task with distractions between each condition. In addition, the study randomized the conditions in order to minimize the ordering effects. While repeated measure design facilitated the 'within subject' comparison between the VWTCRTT and the NVWTCRTT, it may be possible to detect a significant difference with single exposure design. For example, a study by Bushman (1995) found a significant difference in aggression between violent and non-violent media exposure where subjects were assigned to either violent or non-violent conditions. Furthermore, a larger sample would guarantee the significant difference between two conditions.

The present investigation answers a call by Ferguson et al. (2008) to develop a standardized aggression measurement tool. This call was made because inconsistency in aggression research may stem from the inconsistent measurement tool. After an in-depth literature analysis, only intensity was selected as it was suggested that intensity might be the best indicator of aggression (Ferguson et al., 2008; Giancola \& Zeichner, 1995). The pilot study data also showed that having a dual measure of aggression with both intensity and duration is problematic as some subjects - especially younger ones - had a difficult time in controlling both functions. In addition, the WCRTT has advantages over the traditional TCRTT in terms of data coding and data storage as all of the results from the study can be easily stored on a hard drive. Furthermore, given the ease of use of the program, the WCRTT that was developed and tested in this study can be used not only by the scholars interested in aggression research with no cost and but also by the parents who want to monitor their children's state (i.e., behavioral) aggression. For instance, parents can use this WCTRTT after their children are exposed to certain media content and see if their aggression levels are elevated or not.

The current study is grounded in existing research on aggression and media psychology in terms of its research objectives, design, and use of psychometrically sound measures. However, as with most social science research, it has certain limitations which should be noted. For example, in terms of generalizability, the study was conducted with a sample of young people between the ages of 10 and 16 from one region of the United States. Thus, the results of the study may not be generalizable to other groups (e.g., college students in other areas, adult populations). Moreover, because the participants with violence history were excluded from the current study, the findings cannot be generalized to them. Also, because all of the study participants were volunteers who were monetarily compensated for their time, there might be the possibility that certain personality types or characteristics would be more likely to take part in this study for the incentive than others.

The current research suggests several avenues for future studies on the media violence on aggression. As mentioned earlier, there is a need for field experimental study on aggression which will bridge the gap between applied field study and laboratory experimental study. While the current study was administered in a lab setting only because of internal validity purposes, future studies may utilize the program with mobile communication devices (e.g., cell phones) in real settings. It should be also noted that if someone want to use WCRTT outside 
laboratory setting, there is a need for oversight and proper control of the program, including volume of sound blasts, headphones and computer compatibility. For those who use WCRTT for the future studies, there is a need for oversight and proper testing Furthermore, there is a need for studies with a larger sample. While the current study sample size was not small, continued efforts to verify the applicability of the WTCRTT with larger samples will broaden scholars' understanding on aggression measurement. Lastly, future researchers could also look at the WTCRTT cross-culturally to verify its applicability in different cultural settings.

\section{References}

Achterberg, M., van Duijvenvoorde, A. C., BakermansKranenburg, M. J., \& Crone, E. A. (2016). Control your anger! The neural basis of aggression regulation in response to negative social feedback. Social cognitive and affective neuroscience, 11(5), 712-720.

Anderson, C. A. (1995). Implicit personality theories and empirical data: Biased assimilation, belief perseverance and change, and covariation detection sensitivity. Social Cognition, 13, 25-48.

Anderson, C. A., Berkowitz, L., Donnerstein, E., Huesmann, L. R., Johnson, J., Linz, D., Malamuth, N., \& Wartella, E. (2003). The influence of media violence on youth. Psychological Science in the Public Interest, 4(3), 81-110.

Anderson, C. A., \& Bushman, B. J. (1997). External validity of "trivial" experiments: The case of laboratory aggression. Review of General Psychology, 1, 19-41.

Anderson, C. A., \& Dill, K. E. (2000). Video games and aggressive thoughts, feelings, and behavior in the laboratory and in life. Journal of Personality and Social Psychology, 78, 772-790.

Anderson, C. A., Lindsay, J. J., \& Bushman, B. J. (1999). Research in the psychological laboratory: Truth or triviality? Current Directions in Psychological
Science, 8(1), 3-9.

Anderson, C. A., \& Murphy, C. R. (2003). Violent video games and aggressive behavior in young women. Aggressive Behavior, 29, 423-429.

Baron, R., \& Richardson, D. (1994). Human aggression. New York: Plenum Press.

Beal, D. J., Weiss, H. M., Barros, E., \& MacDermid, S. M. (2005). An episodic process model of affective influences on performance. Journal of Applied Psychology, 90, 1054-1068.

Berkowitz, L. (1962). Aggression: A social psychological analysis. New York: McGraw-Hill.

Bernat, J. A., Calhoun, K. S., Adams, H. E., \& Zeichner, A. (2001). Homophobia and physical aggression toward homosexual and hetero sexual individuals. Journal of Abnormal Psychology, 110, 179-187.

Bond, A., \& Lader, M. (1986). A method to elicit aggressive feelings and behavior via provocation. Biological Psychology, 22, 69-79.

Burton L. A., Henniger, D., Hafetz, J., \& Cofer, J. (2009). Aggression, gender-typical childhood play, and a prenatal hormonal index. Social Behavior and Personality, 37(1), 105-116.

Bushman, B. J. (1995). Moderating role of trait aggressiveness in the effects of violent media on aggression. Journal of Personality and Social Psychology, 69(5), 950-960.

Buss, A. H. (1961). The psychology of aggression. New York: Wiley.

Buss, A. H., \& Durkee, A. (1957). An inventory for assessing different kinds of hostility. Journal of Consulting Psychology, 21, 343-349.

Buss, A. H., \& Perry, M. (1992). The aggression questionnaire. Journal of Personality and Social Psychology, 63, 452-459.

Christensen, P. \& Wood, W. (2007). Effects of media violence on viewers' aggression in unconstrained social interaction. In R. W. Preiss, B. M. Gayle, N. Burrell, M. Allen, \& J. Bryant (Eds.), Mass media effects research: Advances through meta-analysis (pp. 145-168). Mahwah, NJ: Erlbaum. 
Clemente, M., Espinosa, P., \& Vidal, M. A. (2008). The media and violent behavior in young people: Effects of the media on antisocial aggressive behavior in a Spanish sample. Journal of Applied Social Psychology, 38(10), 2395-2409.

Coyne, S. M., Padilla-Walker, L. M., Holmgren, H. G., Davis, E. J., Collier, K. M., Memmott-Elison, M. K., \& Hawkins, A. J. (2018). A meta-analysis of prosocial media on prosocial behavior, aggression, and empathic concern: A multidimensional approach. Developmental psychology, 54(2), 331.

Doob, A. N., \& Sprott, J. B. (1998). Is the "quality" of youth violence becoming more serious? Canadian Journal of Criminology, 40(2), 185-194.

Farrar, K., \& Krcmar, M. (2006). Measuring state and trait aggression: A short, cautionary tale. Media Psychology, 8, 127-138.

Ferguson, C. J., Smith, S., Miller-Stratton, H., Fritz, S., \& Heinrich, E. (2008). Aggression in the laboratory: Problems with the validity of the modified Taylor competitive reaction time test as a measure of aggression in media violence studies. Journal of Aggression, Maltreatment \& Trauma, 17(1), 118-132.

Ferguson, C. J., \& Rueda, S. M. (2009). Examining the validity of the modified Taylor competitive reaction time test of aggression. Journal of Experimental Criminology, 5(2), 121-137.

Frost, R., \& Stauffer, J. (1987). The effects of social class, gender, and personality on physiological responses to filmed violence. Journal of Communication, 37(2), 29-45.

Funk, J. B., Baldacci, H. B., Pasold, T., \& Baumgardner, J. (2004). Violence exposure in real-life, video games, television, movies, and the internet: Is there desensitization? Journal of Adolescence, 27, 23-39.

Gay, L .R. (1987). Educational research: Competencies for analysis and application (3rd ed.). New York: MacMillan.

Giancola, P. R., \& Zeichner, A. (1995). Construct validity of a competitive reaction-time aggression paradigm. Aggressive Behavior, 21, 199-204.

Gunter, B. (1994). The question of media violence. In Jennings, B., \& Zillmann, D. (Eds.), Media effects (pp. 163-212). Hillsdale, NJ: Lawrence Erlbaum.

Gustafson, R. (1991). Aggressive and nonaggressive behavior as a function of alcohol intoxication and frustration in women. Alcoholism: Clinical and Experimental Research, 15, 886-892.

Haridakis, P. M. (2006). Men, women, and televised violence: Predicting viewer aggression in male and female television viewers. Communication Quarterly, 54(2), 227-255.

Konijin, E. A., Bijvank, M. N., \& Bushman, B. J. (2007). I wish I were a warrior: The role of wishful identification in the effects of violent video games on aggression in adolescent boys. Developmental Psychology, 43(4), 1038-1044.

Krcmar, M., \& Greene, K. (1999). Predicting exposure to and uses of violent television. Journal of Communication, 49, 25-45.

Lang, A. (1990). Involuntary attention and psychophysiological arousal evoked by structural features and mild emotion in TV commercials. Communication Research, 17, 275-299.

LaBrie, R. A., Shaffer, H. J., LaPlante, D. A., \& Wechsler, H. (2003). Correlates of college student gambling in the United States. Journal of American College Health, 52(2), 53-62.

Marsee, M. A., Weems, C. F., \& Taylor, L. K. (2008). Exploring the association between aggression and anxiety in youth: A look at aggressive subtypes, gender, and social cognition. Journal of Child and Family Studies, 17, 154-168.

Nathanson, A. I. (1999). Identifying and explaining the relationship between parental mediation and children's aggression. Communication Research, 26, 124-143.

Ostrov, J. M., Gentile, D. A., \& Crick, N. R. (2006). Media exposure, aggression and prosocial behavior during early childhood: A longitudinal study. Social Development, 15(4), 612-627. 
Padilla, A. J., Bentolila, S., \& Dolado, J. J. (2005). Wage bargaining in industries with market power. Journal of Economics \& Management Strategy, 5(4), 535564.

Poels, K., \& Dewitte, S. (2006). How to capture the heart? Reviewing 20 years of emotion measurement in advertising. Journal of Advertising Research, 46, 18-37.

Reidy, D. E., Dimmick, K., MacDonald, K., \& Zeichner, A. (2009). The relationship between pain tolerance and trait aggression: Effects of sex and gender role. Aggressive Behavior, 35, 422-429.

Scariano, S. M., \& Davenport, J. M. (1987). The effects of violations of independence in the one-way ANOVA. The American Statistician, 41(2), 123-129.

Sherry, J. L. (2001). The effects of violent video games on aggression: A meta-analysis. Human Communication Research, 27, 409-431.

Slater, M. D., Henry, K. L., Swaim, R. C., \& Anderson, L. L. (2003). Violent media content and aggressiveness in adolescents: A downward spiral model. Communication Research, 30, 713-736.
Stadler, C., Rohrmann, S., Steuber, S., \& Roustka, F. (2006). Effects of provocation on emotions and aggression: An experimental study with aggressive children. Swiss Journal of Psychology, 65(2), 117-124.

Taylor, S. P. (1967). Aggressive behavior and physiological arousal as a function of provocation and the tendency to inhibit aggression. Journal of Personality, 35, 297-310.

Tedeschi, J. T., \& Quigley, B. M. (1996). Limitations of laboratory paradigms for studying aggression. Aggression and Violent Behavior, 1(2), 163-177.

Tremblay, R. E., Vitaro, F., \& Côté, S. M. (2018). Developmental origins of chronic physical aggression: A bio-psycho-social model for the next generation of preventive interventions. Annual review of psychology, 69, 383-407.

Zeichner, A., \& Phil, R. (1979). Effects of alcohol and behavior contingencies on human aggression. Journal of Abnormal Psychology, 88, 153-160. 